\title{
Subclinical Iodine Deficiency among Pregnant Women in Haramaya District, Eastern Ethiopia: A Community-Based Study
}

\author{
Haji Kedir, ${ }^{1}$ Yemane Berhane, ${ }^{2}$ and Alemayehu Worku ${ }^{3}$ \\ ${ }^{1}$ College of Health and Medical Sciences, Haramaya University, P.O. Box 235, Harar, Ethiopia \\ ${ }^{2}$ Addis Continental Institute of Public Health, Addis Ababa, Ethiopia \\ ${ }^{3}$ School of Public Health, Addis Ababa University, P.O. Box 26751/1000, Addis Ababa, Ethiopia \\ Correspondence should be addressed to Haji Kedir; hajikedir2007@yahoo.com
}

Received 12 April 2014; Accepted 25 June 2014; Published 17 July 2014

Academic Editor: C. S. Johnston

Copyright (C) 2014 Haji Kedir et al. This is an open access article distributed under the Creative Commons Attribution License, which permits unrestricted use, distribution, and reproduction in any medium, provided the original work is properly cited.

\begin{abstract}
Background. Iodine deficiency in pregnancy is a worldwide problem. This study aimed to assess prevalence and predictors of subclinical iodine deficiency among pregnant women in Haramaya district, eastern Ethiopia. Methods. A cross-sectional, communitybased study was conducted on 435 pregnant women existing in ten randomly selected rural kebeles (kebele is the smallest administrative unit in Ethiopia). Data on the study subjects' background characteristics, dietary habits, and gynecological/obstetric histories were collected via a structured questionnaire. UIC of $<150 \mu \mathrm{g} / \mathrm{L}$ defined subclinical iodine deficiency. Data were analyzed by Stata 11. A multivariable logistic regression was used to identify the predictors of subclinical iodine deficiency. Results. The median urinary iodine concentration (MUIC) was $58.1 \mu \mathrm{g} / \mathrm{L}$ and $82.8 \%$ of the women who had subclinical iodine deficiency. The risk of subclinical iodine deficiency was reduced by the use of iodized salt $(\mathrm{AOR}=0.13)$ and by intake of milk twice a month or more $(\mathrm{AOR}=0.50)$, but it was increased by maternal illiteracy $(\mathrm{AOR}=3.52)$. Conclusion. Iodine nutritional status of the pregnant women was poor. This shows that women and their children are exposed to iodine deficiency and its adverse effects. Thus, they need urgent supplementation with iodine and improved access to and intake of iodized salt and milk during pregnancy.
\end{abstract}

\section{Background}

Iodine is an essential nutrient which is used in the synthesis of thyroid hormones that are important for the normal development of the nervous system [1]. Its inadequate intake brings iodine deficiency disorders (IDD) and hypothyroidism, either clinical or subclinical, is one of them [2]. Previous researchers have reported that during pregnancy, mild iodine deficiency causes maternal hypothyroxinemia that is related to mild and subclinical cognitive and psychomotor deficit in neonates, infants, and children [3]. Several others have shown that severe iodine deficiency during pregnancy increases the risk of spontaneous abortion, stillbirth, reduced intelligence, neurological cretinism, poor cognitive functions, and delayed psychomotor developments $[1,2,4,5]$.

Nearly two billion (28\%) of the world's population, of whom more than 321 million (39\%) are Africans, are at risk of insufficient iodine intake [6]. Based on the global data of iodine nutrition, Ethiopia is categorized among moderately iodine deficient countries [6]. Similarly, Ethiopia is one of the African countries with the highest prevalence of IDD and with the weakest program to prevent IDD [7]. From 34.5\% to $37 \%$ of the childbearing women in the country have goiter [8].

Because of the higher production and fetal transfer of maternal thyroid hormone, fetal iodine transfer, and raised renal iodine clearance [9], pregnant women need more iodine than their counterparts do. They are required to consume $250 \mu \mathrm{g}$ of iodine a day [10]. However, they hardly meet their requirement solely from the usual diets $[10,11]$.

Universal salt iodization (USI) is the most cost effective strategy recommended to eliminate IDD $[12,13]$. However, more than one-third of the African households do not have access to iodized salt [14]. Only $20 \%$ of the Ethiopian households use adequately iodized salt [15]. Thus, iodine deficiency has been identified as a serious public health problem for the Ethiopian population. As a result a national regulatory provision for mandatory universal salt iodization was offered in 2011. 
Still, hardly any of the previous studies done on the problem in Ethiopia have considered subclinical iodine deficiency in pregnant women. Therefore, this study aimed to determine median urinary iodine concentration, prevalence of subclinical iodine deficiency, and factors associated with iodine deficiency among the pregnant women in rural communities of Haramaya district of eastern Ethiopia.

\section{Methods}

2.1. Study Setting, Design, and Period. A community-based cross-sectional study was done in Haramaya district, eastern Ethiopia, from March 16 to 29, 2012. The district is 1400-2340 meters above sea level. It is divided into 4 semiurban kebeles and 33 rural kebeles (the lowest administrative units) and has a population of about 271,018 people, of whom more than $96 \%$ are Oromo in ethnicity and Muslim. We have described the study area in more detail in the previously published article [16].

2.2. Study Population, Sample Size, and Sampling. Pregnant women in the randomly selected rural kebeles of the district were the study population. Pregnant women were identified by self-report, from the report of health extension workers in the kebeles and urine testing when pregnancy was doubtful. The sample size was estimated by assuming a 50\% subclinical iodine deficiency, a 95\% confidence interval, a 5\% margin of error, and a $15 \%$ nonresponse rate and this yielded a sample size of 443. According to Andersen et al., a sample size of 500 subjects is adequate to assess iodine nutrition of the population from spot samples [17].

This study is a subsample of a prospective cohort study of the effects of maternal nutrition on birth outcomes. It was based on random subsample of ten of the twelve kebeles selected for the cohort study. To select the kebeles (primary sampling units), all the rural kebeles in the district $(n=33)$ were listed and each was assigned a unique number. Then, a simple random sampling technique was applied to select the twelve kebeles for the cohort study. Finally, the list of the twelve kebeles was considered as a sampling frame and ten kebeles were randomly selected from it. Cognizing the little difference between the larger estimated sample size $(n=500)$ and the number of the pregnant women in the ten selected kebeles $(n=525)$, we recruited all of them.

2.3. Data Collection Methods and Procedures. Eight college graduates collected the data and two public health professionals and the principal investigator supervised the fieldwork. The respondents' sociodemographic, reproductive history and dietary characteristics were obtained via a pretested and interviewer-administered questionnaire. The items included in the questionnaire were taken from the Ethiopian Health and Demographic Survey (EDHS) and were adapted to suit the study context.

A teaspoon of salt sample was taken from each household of the respondent and tested for contents of iodine, using a rapid test kit distributed by UNICEF for the purpose of assessing household salt iodine content. The rapid test kit comprises test solution and a color chart. We put a drop of the test solution on each salt sample. Then, salt samples that immediately turned into a purple blue color of any intensity as shown on the color chart after putting a drop of test solution were classified as containing iodine and those not remaining unchanged after putting a drop of test solution were classified as not containing iodine.

A $10 \mathrm{~mL}$ urine sample was taken from each study subject in wide-opened plastic caps covered by an opaque paper bag and transferred into a labeled, clean tightly sealed plastic tubes that were free from iodine or any other chemical to avoid leakage and cross-contaminations with iodine from other sources. The urine samples were kept in a cold box and transported to iodine laboratory at Ethiopian Health and Nutrition Research Institute (EHNRI) under the cold chain. In the national laboratory of food and nutrition research at ENHRI, duplicates of each urine sample brought from each pregnant women were prepared and the determination of urinary iodine concentration was made using the duplicate samples. The Sandell-Kolthoff reaction method which is recommended by World Health Organization (WHO), United Nations Children's Fund (UNICEF), and International Council for the Control of Iodine Deficiency Disorders (ICCIDD) was used to determine the UIC [18]. The method is described in further detail by the publication of WHO [18].

2.4. Statistical Analysis. Data were double-entered and validated by EpiData Version 3.1. Stata 11 and SPSS V. 16 were used to analyze the data. Using Mann-Whitney $U$ test or KruskalWallis test, we compared the median and the UIC between groups of categorical independent variables. Through bivariate and multivariable logistic regressions, the predictors of subclinical iodine deficiency (UIC $<150 \mu \mathrm{g} / \mathrm{L}$ ) were identified. Variables were included into the multivariable model based on the existing literature about their suspected effects on subclinical iodine deficiency and its predictors. In order to avoid confounding factors, the enter method of logistic regression was used and the risk estimates were adjusted for all the variables entered. A two-sided $P$ value of $<0.05$ was considered to declare statistical significance.

WHO recommends urinary iodine concentrations of $<150,150-249,250-499$, and $\geq 500 \mu \mathrm{g} / \mathrm{L}$ that should be used to indicate insufficient, adequate, more than adequate, and excessive levels of iodine intake in population of pregnant women [19]. In this study, UIC $<150 \mu \mathrm{g} / \mathrm{L}$ defined subclinical iodine deficiency and value $\geq 150 \mu \mathrm{g} / \mathrm{L}$ absence of subclinical iodine deficiency. Median UIC and subclinical iodine deficiency were the dependent variables. The group with $<150 \mu \mathrm{g} / \mathrm{L}$ were further categorized into $<20 \mu \mathrm{g} / \mathrm{L}$ (severe iodine deficiency), 20-49 $\mu \mathrm{g} / \mathrm{L}$ (moderate iodine deficiency), and 50-149 $\mu \mathrm{g} / \mathrm{L}$ (mild iodine deficiency) [20]. The independent variables and covariates examined for their association with subclinical iodine deficiency were maternal age, educational status, family size, possession of milk cows, consumption of milk, consumption of cabbage, household use of iodized salt, prenatal visit, trimester of pregnancy, and number of pregnancies.

2.5. Ethics. The Institutional Review Board (IRB) of Haramaya University and the National Research Ethics Review 
TABLE 1: Characteristics of pregnant women in Haramaya, eastern Ethiopia, April, 2012.

\begin{tabular}{|c|c|c|c|c|}
\hline Variable & $\begin{array}{c}\text { Total } \\
\text { Frequency (\%) }\end{array}$ & $\begin{array}{c}\text { No iodine deficiency } \\
\text { Frequency }(\%)\end{array}$ & $\begin{array}{c}\text { Iodine deficiency } \\
\text { Frequency (\%) }\end{array}$ & $P$ value ${ }^{*}$ \\
\hline Age group & & & & 0.100 \\
\hline 18-24 years & $126(28.97)$ & $18(14.29)$ & $108(85.71)$ & \\
\hline 25-34 years & $241(55.40)$ & $39(16.18)$ & $202(83.82)$ & \\
\hline $35-49$ years & $68(15.63)$ & $18(26.47)$ & $50(73.53)$ & \\
\hline Educational status & & & & 0.213 \\
\hline Literate & $31(7.13)$ & $8(25.81)$ & $23(74.19)$ & \\
\hline Illiterate & $404(92.87)$ & $67(16.58)$ & $337(83.42)$ & \\
\hline Family size & & & & 0.636 \\
\hline$<5$ persons & $41(18.06)$ & $41(18.06)$ & $186(81.94)$ & \\
\hline$\geq 5$ persons & $34(16.35)$ & $34(16.35)$ & $174(83.65)$ & \\
\hline Previous pregnancies & & & & 0.281 \\
\hline 0 & $87(20.00)$ & $12(13.79)$ & $75(86.21)$ & \\
\hline $1-3$ & $280(64.37)$ & $47(16.79)$ & $233(83.21)$ & \\
\hline$\geq 4$ & $68(15.63)$ & $16(23.53)$ & $52(76.47)$ & \\
\hline Pregnancy trimester & & & & 0.694 \\
\hline First & $52(11.95)$ & $9(17.31)$ & $43(82.69)$ & \\
\hline Second & $169(38.85)$ & $26(15.38)$ & $143(84.62)$ & \\
\hline Third & $214(49.20)$ & $40(18.69)$ & $174(81.31)$ & \\
\hline Possessed milk cows & & & & 0.189 \\
\hline No cow & $171(39.31)$ & $26(15.20)$ & $145(84.80)$ & \\
\hline One cow & $124(28.51)$ & $28(22.58)$ & $96(77.42)$ & \\
\hline Two or more cows & $140(32.18)$ & $21(15.00)$ & $119(85.00)$ & \\
\hline Prenatal visit & & & & 0.440 \\
\hline No & $112(25.75)$ & $22(19.64)$ & $90(80.36)$ & \\
\hline Yes & $323(74.25)$ & $53(16.41)$ & $270(83.59)$ & \\
\hline Cabbage consumption & & & & 0.019 \\
\hline$<1$ serving/week & $334(76.78)$ & $65(19.46)$ & $269(80.54)$ & \\
\hline$\geq 1$ serving/week & $101(23.22)$ & $10(9.90)$ & $91(90.10)$ & \\
\hline Household salt & & & & $<0.0001$ \\
\hline Not iodized & $406(93.33)$ & $62(15.27)$ & $344(84.73)$ & \\
\hline Iodized & $29(6.67)$ & $13(44.83)$ & $16(55.17)$ & \\
\hline Consumption of milk & & & & 0.500 \\
\hline$<3$ times/month & $230(52.87)$ & 37 (16.09) & $193(83.91)$ & \\
\hline$\geq 3$ times/month & $205(47.13)$ & $38(18.54)$ & $167(81.46)$ & \\
\hline
\end{tabular}

${ }^{*} P$ values are based on likelihood ratio chi-square test.

Committee of Ethiopia reviewed and approved the protocol. All the study participants provided their written informed consent. The purposes, the data collection procedures, the risks, and the benefits of the research were explained to the eligible respondents before obtaining their informed consent.

\section{Results}

3.1. Sociodemographic Characteristics. Of the 525 pregnant women recruited, 435 were included in the analysis and the response rate was $82.8 \%$. The remaining 90 pregnant women did not give their urine and they were not different from the women included in the analysis in their sociodemographic characteristics. Nearly all of the respondents were Oromo (99.5\%) and Muslim (99.3\%). Their mean age and duration of pregnancy were $27.0(\mathrm{SD} \pm 5.9)$ years and $25.8(\mathrm{SD} \pm 5.8)$ weeks, respectively. The characteristics of women participating in this study are detailed in Table 1.

Urinary Iodine Concentration and Associated Factors. The median UIC was $58.1 \mu \mathrm{g} / \mathrm{L}$ (interquartile range $(\mathrm{IQR})=21.4-$ 111.1). The women in the households which used iodized salt more than those in the households that did not and women who consumed milk at least twice a month more than those who never did so had significantly higher median UIC (Mann-Whitney $U$ test, $P<0.05$ ) (Table 2). However, the median UIC did not show significant associations with the respondents' educational status, parity levels, trimester of pregnancy, and other sociodemographic characteristics studied (Table 2). 
TABLE 2: Distribution of median urinary iodine concentration of pregnant women with selected variables, Haramaya, April 2012.

\begin{tabular}{|c|c|c|c|c|c|}
\hline Variable & Percent & $\operatorname{Median}(\mu \mathrm{g} / \mathrm{L})$ & $\mathrm{Q} 1(\mu \mathrm{g} / \mathrm{L})$ & Q3 $(\mu \mathrm{g} / \mathrm{L})$ & $P$ value \\
\hline Age groups & & & & & $0.355^{* *}$ \\
\hline 18-24 years & 28.97 & 54.47 & 19.30 & 97.97 & \\
\hline $25-34$ years & 55.40 & 68.66 & 25.56 & 151.89 & \\
\hline 35 years or older & 15.63 & 68.66 & 25.56 & 151.89 & \\
\hline Education & & & & & $0.776^{*}$ \\
\hline Literate & 7.13 & 64.13 & 23.79 & 150.75 & \\
\hline Illiterate & 92.87 & 57.80 & 20.47 & 109.68 & \\
\hline Number of births & & & & & $0.168^{* *}$ \\
\hline 0 & 20.00 & 49.37 & 18.84 & 96.79 & \\
\hline $1-3$ & 64.37 & 56.78 & 20.34 & 111.84 & \\
\hline$>4$ & 15.63 & 68.89 & 31.84 & 138.72 & \\
\hline Trimester & & & & & $0.743^{* *}$ \\
\hline First & 11.95 & 61.87 & 24.84 & 114.25 & \\
\hline Second & 38.85 & 58.07 & 27.33 & 94.00 & \\
\hline Third & 49.20 & 55.91 & 13.86 & 113.79 & \\
\hline Prenatal visit & & & & & $0.348^{*}$ \\
\hline No & 25.75 & 42.84 & 18.99 & 124.32 & \\
\hline Yes & 74.25 & 58.78 & 23.27 & 110.87 & \\
\hline Milk cows & & & & & $0.971^{* *}$ \\
\hline 0 & 39.31 & 58.34 & 21.70 & 103.04 & \\
\hline 1 & 28.51 & 54.20 & 20.92 & 126.87 & \\
\hline $2+$ & 32.18 & 57.95 & 19.47 & 113.18 & \\
\hline Milk intake & & & & & $0.023^{*}$ \\
\hline$<3$ times/month & 52.87 & 47.76 & 15.70 & 104.22 & \\
\hline$\geq 3$ times/month & 47.13 & 69.14 & 27.11 & 113.98 & \\
\hline Cabbage use & & & & & $0.051^{*}$ \\
\hline$<1 /$ week & 76.78 & 58.42 & 23.35 & 114.28 & \\
\hline$\geq 1$ /week & 23.22 & 52.10 & 8.23 & 89.67 & \\
\hline Household salt & & & & & $0.018^{*}$ \\
\hline Not iodized & 93.33 & 56.57 & 20.37 & 103.56 & \\
\hline Iodized & 6.67 & 114.08 & 28.40 & 195.64 & \\
\hline Family size & & & & & $0.669^{*}$ \\
\hline$<5$ persons & 52.18 & 58.07 & 19.45 & 103.31 & \\
\hline$\geq 5$ persons & 47.82 & 57.93 & 23.46 & 113.45 & \\
\hline
\end{tabular}

Subclinical Iodine Deficiency and Its Predictors. In this study, $360(82.8 \%)$ respondents had subclinical iodine deficiency. Of the total respondents, $40(9.2 \%), 35(8.0 \%)$, and none had adequate, more than adequate, and excessive iodine intakes, respectively. When the levels of subclinical iodine deficiency were further categorized, 105 (24.1\%), 91 (20.9\%), and 164 (37.7\%) of all respondents had UIC of $<20 \mu \mathrm{g} / \mathrm{L}$ (severe iodine deficiency), 20-49 $\mu \mathrm{g} / \mathrm{L}$ (moderate iodine deficiency), and 50-149 $\mu \mathrm{g} / \mathrm{L}$ (mild iodine deficiency), respectively.

In the bivariate analysis, the risk of subclinical iodine deficiency was significantly low among the women who were 35 to 49 years of age, who consumed milk at least three times a month, who eat cabbage once a week or more frequently, and who were from households which used iodized salt (Table 3).

In a multivariable analysis, the factors significantly associated with subclinical iodine deficiency at the bivariate still remained significant. Thus, the respondents who used iodized salt had $87 \%$ lower risk of subclinical iodine deficiency than their counterparts who did not and those who consumed milk at least twice a month had a 50\% lower risk of the deficiency (Table 3). The risk of subclinical iodine deficiency increased by more than threefold in illiterate women than literate ones and in women within a family size of five or more than in those within family size below five, while the magnitude of subclinical iodine deficiency was significantly reduced with increased parity level (Table 3).

\section{Discussion}

The study showed a high prevalence of subclinical iodine deficiency, a low median UIC, and a low proportion of households with iodized salt, while consuming iodized salt 
TABLE 3: Factors associated with subclinical iodine deficiency in logistic regression analysis among pregnant women, Haramaya, April 2012.

\begin{tabular}{|c|c|c|c|c|}
\hline Variable & Crude OR (95\% CI) & $P$ value ${ }^{*}$ & Adjusted OR $(95 \% \text { CI })^{\dagger}$ & $P$ value ${ }^{*}$ \\
\hline \multicolumn{5}{|l|}{ Age group } \\
\hline 18-24 years & 1 & & 1 & \\
\hline $25-34$ years & $0.86(0.47,1.58)$ & 0.634 & $0.59(0.29,1.19)$ & 0.138 \\
\hline 35-49 years & $0.46(0.22,0.96)$ & 0.040 & $0.30(0.12,0.75)$ & 0.010 \\
\hline \multicolumn{5}{|l|}{ Educational status } \\
\hline Literate & 1 & & 1 & \\
\hline Illiterate & $1.75(0.75,4.08)$ & 0.195 & $3.52(1.30,9.55)$ & 0.013 \\
\hline \multicolumn{5}{|l|}{ Family size } \\
\hline$<5$ persons & 1 & & 1 & \\
\hline$\geq 5$ persons & $1.13(0.68,1.86)$ & 0.636 & $3.22(1.57,6.58)$ & 0.001 \\
\hline \multicolumn{5}{|l|}{ Previous pregnancies } \\
\hline 0 & 1 & & 1 & \\
\hline $1-3$ & $0.79(0.40,1.57)$ & 0.508 & $0.36(0.15,0.82)$ & 0.016 \\
\hline$\geq 4$ & $0.52(0.23,1.19)$ & 0.122 & $0.23(0.07,0.74)$ & 0.013 \\
\hline \multicolumn{5}{|l|}{ Trimester of pregnancy } \\
\hline First & 1 & & 1 & \\
\hline Second & $1.15(0.50,2.64)$ & 0.740 & $0.97(0.38,2.46)$ & 0.942 \\
\hline Third & $0.91(0.41,2.02)$ & 0.817 & $0.78(0.32,1.89)$ & 0.582 \\
\hline \multicolumn{5}{|l|}{ Possessed milk cows } \\
\hline No cow & 1 & & 1 & \\
\hline One cow & $0.61(0.34,1.11)$ & 0.108 & $0.41(0.21,0.81)$ & 0.010 \\
\hline Two or more cows & $1.02(0.54,1.90)$ & 0.960 & $0.78(0.38,1.61)$ & 0.503 \\
\hline \multicolumn{5}{|l|}{ Prenatal visit } \\
\hline No & 1 & & 1 & \\
\hline Yes & $1.25(0.72,2.16)$ & 0.436 & $1.85(0.92,3.70)$ & 0.083 \\
\hline \multicolumn{5}{|l|}{ Cabbage consumption } \\
\hline$<3$ times/month & 1 & & 1 & \\
\hline$\geq 3$ times/month & $2.20(1.08,4.46)$ & 0.029 & $3.04(1.37,6.77)$ & 0.006 \\
\hline \multicolumn{5}{|l|}{ Household salt } \\
\hline Not iodized & 1 & & 1 & \\
\hline Iodized & $0.22(0.10,0.48)$ & $<0.001$ & $0.13(0.05,0.32)$ & $<0.0001$ \\
\hline \multicolumn{5}{|l|}{ Consumption of milk } \\
\hline$<3$ times/month & 1 & & 1 & \\
\hline$\geq 3$ times/month & $0.84(0.51,1.39)$ & 0.500 & $0.50(0.27,0.93)$ & 0.029 \\
\hline
\end{tabular}

${ }^{*} P$ values are based on likelihood chi-square test; ${ }^{\dagger}$ adjusted for all variables shown in the table; OR: odds ratio; CI: confidence interval.

and milk that were predictors of higher UIC and were associated with reduced prevalence of subclinical iodine deficiency. Lack of education among pregnant women was associated with a threefold increased risk of subclinical iodine deficiency.

Recently, other researchers working in the Sidama Zone of southern Ethiopia on 172 pregnant women have witnessed that iodized salt is not used in higher than $90 \%$ of the households and $60 \%$ of the respondents had UIC lower than $20 \mu \mathrm{g} / \mathrm{L}$ and the median UIC of $15 \mu \mathrm{g} / \mathrm{L}$ [21]. Compared to the study from southern Ethiopia, the present study observed lower proportion of pregnant women with UIC less than $20 \mu \mathrm{g} / \mathrm{L}$ and a higher median UIC [21]. Nevertheless, both studies indicate that iodine deficiency is unacceptably high in Ethiopian pregnant women. The differences between the findings of our study conducted in eastern Ethiopia and the study from the southern Ethiopia could be explained by sociocultural and ecological differences and the compositions of the study subjects enrolled in the two studies. The variations could also indicate the need of regional studies with detailed investigation of risk factors specific to particular locality or a nationwide study with representative coverage of different regions and contextual risk factors.

High level of iodine deficiency has been witnessed by previous clinical and subclinical assessments made on samples of school-aged children $[22,23]$. For example, a median UIC of $56 \mu \mathrm{g} / \mathrm{L}$ and $34.2 \mu \mathrm{g} / \mathrm{L}$ is reported from southwestern and southern Ethiopia, respectively [22, 23]. Despite the differences in the study subjects, the findings from the present study were confirmations of the degree of iodine deficiency in Ethiopia.

Like other authors, we observed that household salt iodization significantly reduces the risk of iodine deficiency $[24,25]$. However, low proportion of iodized salt utilization at 
the household level reported in our study calls for urgent need of coordinated efforts. Our study and other previous studies demonstrated that milk is an important source of iodine $[25,26]$, and this strengthens the promotion of the intake of milk and other dairy products during or before prenatal period and of the importance of possessing milk cows at the household level in the communities like ours that do not have ease of access to fish and other sea foods. In our study, the illiterate study subjects were more likely to be iodine deficient than the literate ones. It has also been demonstrated by other authors that better educated pregnant women are more likely to consume food with higher dietary quality index [27]. The decrease of the UIC in advanced stages of pregnancy that have been demonstrated by several others [28-30] was not confirmed by the present study. This could be due to the small number of respondents with the first trimester of pregnancy in the present study.

Unlike the understanding of the negative effect of repeated pregnancy on maternal nutritional status, in this study the risk of subclinical iodine deficiency decreased with an increase in the number of pregnancy experiences. This could be explained by the possibility that pregnant women with more pregnancy experiences could receive nutrition related information from various sources during their previous pregnancy experience and as a result they may have higher iodine intake [31].

Our study might have had some limitations. The questionnaire based assessment of dietary iodine intake and other data might not be as accurate as it should be. Moreover, as UIC can only indicate the present iodine nutrition, the findings might not reflect levels of chronic iodine deficiency. To get an insight on long standing iodine deficiency, it would have been better if the prevalence of goiter had also been assessed. Furthermore, UIC data cannot tell thyroid function in the group of women studied, which could only be possible with determination of thyroid hormones. The data on thyroid hormones and prevalence of goiter were not possible to obtain with the resource available for the present study. Nevertheless, the data are important for better understanding of the iodine deficiency in this community. Another limitation is that this study is a cross-sectional study conducted during the hot season which might lead to the underestimation of iodine deficiency and overestimation of median urinary iodine concentration as a result of seasonal variation in urinary iodine concentration that increases during the dry hot season [32]. In addition, the household salt iodization test was qualitative; it did not provide iodine concentration. Even though it has been recommended that salt samples identified as containing iodine based on the color change should be further examined through iodiometric titration for the quantification of iodine content and evaluation of its adequacy [18], this was not done in the present study, because only a few samples were found to contain iodine based on the rapid test and further classification of such a small number would make further analysis impossible. Had it not been for the resource limitation, we could have considered design effect to account for the cluster based sampling. However, the effect of this problem could be minimal due to the inclusion of all pregnant women that were identified in each selected kebele.
Regardless of its limitations, the present study contributed to the global body of knowledge by establishing the Ethiopian data on UIC and iodine nutrition among pregnant women. It is a contribution of Ethiopian context to the global body of knowledge regarding iodine deficiency during pregnancy $[33,34]$.

This study also revealed high prevalence of subclinical iodine deficiency and the scarcity of iodized salt usage among the households in eastern Ethiopia using the two simple and practical methods recommended [35]. Therefore, the findings have implications for public policy, health service provision, self-care, and future research work.

The legislation of Universal Salt Iodization (USI) law is an indication of political commitment and is a corner stone in the prevention of iodine deficiency, but it may not be adequate enough as a self-standing strategy to meet the goal. A number of previous studies have reported persistent occurrence of IDD in pocket geographical locations of countries, regardless of the USI law in place [36]. The same authors witnessed that public awareness about the importance of iodized salt and appropriate handlings of salt at household level are also important factors [36].

The level of subclinical iodine deficiency reported here raises policy concerns for effective interventions. This study could serve the policy on salt iodization to monitor progress and implementation. The health care workers can use the findings to initiate appropriate interventions during prenatal services and to counsel clients to improve their iodized salt and milk intake. Based on international criteria for intervention [37], the findings of the present study strongly indicate the need of iodine supplementation to the pregnant women in the area.

\section{Conclusion}

There was moderate to mild iodine deficiency among the pregnant women in the study area. The poor iodine nutritional status of the women resulted from low iodine intake and this in turn was caused by the scarcity of iodized salt utilization in this community. Therefore, there is an urgent need for iodine supplementation to the pregnant women in the setting. Enhancing access to iodized salt and the promotion of its health benefits are priority interventions that need serious attention. Interventions should also focus on young women, on women with no education, and on those with first time pregnancy. Encouraging milk consumption and improving household livestock raring, with particular emphasis to milk cows is also vital.

\section{Abbreviations}

AOR: Adjusted odds ratio

CI: $\quad$ Confidence interval

EDHS: Ethiopian Health and Demographic Survey

EHNRI: Ethiopian Health and Nutrition Research Institute

ICCIDD: International Council for Control of Iodine Deficiency Disorders 
IDD: Iodine deficiency disorders

UIC: $\quad$ Urinary iodine concentration

UNICEF: United Nations Children's Fund

USI: Universal salt iodization

WHO: World Health Organization.

\section{Conflict of Interests}

The authors did not receive payments, funding, or salary from any organization in relation to the work and publication of this paper in the past five years and there will also be no financial support to be received in the future. There is not any organization affected positively or negatively by the publication of this paper. There are not any competing interests related with patents of the content of the paper. The authors also declare that there are not any other financial or nonfinancial competing interests.

\section{Authors' Contribution}

All authors, Haji Kedir, Yamane Berhane, and Alemayehu Worku, conceptualized the research question, monitored and managed fieldwork, analyzed and interpreted the findings, and written the paper.

\section{Acknowledgments}

Haramaya University provided financial and other supports for this research project. The authors thank EHNRI for laboratory facility. The authors are grateful to the pregnant women who sacrificed their time. The authors acknowledge Eastern Hararghe Zone Health Department for its cooperation and for providing them with cold boxes and icepacks used for keeping and transporting the urine samples. The authors got enabling cooperation from Haramaya District Administration, District Health Office, and the Administrations of the Selected Kebeles during the fieldwork.

\section{References}

[1] C. Yarrington and E. N. Pearce, "EN: iodine and pregnancy," Journal of Thyroid Research, vol. 2011, Article ID 934104, 8 pages, 2011.

[2] M. B. Zimmermann, "Iodine deficiency," Endocrine Reviews, vol. 30, pp. 376-408, 2009.

[3] C. Trumpff, J. De Schepper, J. Tafforeau, H. Van Oyen, J. Vanderfaeillie, and S. Vandevijvere, "Mild iodine deficiency in pregnancy in Europe and its consequences for cognitive and psychomotor development of children: a review," Journal of Trace Elements in Medicine and Biology, vol. 27, no. 3, pp. 174183, 2013.

[4] M. B. Zimmermann, "The effects of iodine deficiency in pregnancy and infancy," Paediatric and Perinatal Epidemiology, vol. 26, supplement 1, pp. 108-117, 2012.

[5] A. Melse-Boonstra and N. Jaiswal, "Iodine deficiency in pregnancy, infancy and childhood and its consequences for brain development," Best Practice \& Research Clinical Endocrinology \& Metabolism, vol. 24, no. 1, pp. 29-38, 2010.

[6] M. Andersson, V. Karumbunathan, and M. B. Zimmermann, "Global iodine status in 2011 and trends over the past decade," Journal of Nutrition, vol. 142, no. 4, pp. 744-750, 2011.
[7] I. Hussein and V. Assey, Elimination of Iodine Deficiency through Salt Iodization in Ethiopia, ICCIDD, Addis Ababa, Ethiopia, 2012.

[8] C. Abuye and Y. Berhane, "The goitre rate, its association with reproductive failure, and the knowledge of iodine deficiency disorders (IDD) among women in Ethiopia: cross-section community based study," BMC Public Health, vol. 7, article 316, 2007.

[9] M. B. Zimmermann, "The role of iodine in human growth and development," Seminars in Cell and Developmental Biology, vol. 22, pp. 645-652, 2011.

[10] M. Andersson, B. D. Benoist, F. Delange, and J. Zupan, "WHO Secretariat on behalf of the participants to the Consultation: Prevention and control of iodine deficiency in pregnant and lactating women and in children less than 2-years-old: conclusions and recommendations of the Technical Consultation," Public Health Nutrition, vol. 10, no. 12, pp. 1606-1611, 2007.

[11] M. B. Zimmermann, "Iodine deficiency in pregnancy and the effects of maternal iodine supplementation on the offspring: a review," The American Journal of Clinical Nutrition, vol. 89, supplement, pp. 668S-672S, 2009.

[12] UNICEF: The State of the World's Children 2009: Maternal and Newborn Health, United Nations Children's Fund, New York, NY, USA, 2008.

[13] V. D. Assey, S. Peterson, S. Kimboka et al., "Tanzania national survey on iodine deficiency: impact after twelve years of salt iodation," BMC Public Health, vol. 9, article 319, 2009.

[14] M. Andersson, Bd. Benoist, and L. Rogers, "Epidemiology of iodine deficiency: salt iodisation and iodine status," Best Practice \& Research: Clinical Endocrinology, vol. 24, pp. 1-11, 2010.

[15] Central Statistical Agency [Ethiopia], "Ethiopia Demographic and Health Survey 2005," Addis Ababa, Ethiopia and Calverton, Md, USA: Central Statistical Agency and ORC Macro. 2006.

[16] H. Kedir, Y. Berhane, and A. Worku, "Khat chewing and restrictive dietary behaviors are associated with anemia among pregnant women in high prevalence rural communities in Eastern Ethiopia," PLoS ONE, vol. 8, no. 11, Article ID e78601, 2013.

[17] S. Andersen, J. Karmisholt, K. M. Pedersen, and P. Laurberg, "Reliability of studies of iodine intake and recommendations for number of samples in groups and in individuals," British Journal of Nutrition, vol. 99, no. 4, pp. 813-818, 2008.

[18] WHO, UNICEF, and ICCIDD, Assessment of Iodine Deficiency Disorders and Monitoring their Elimination: A Guide for Programme Managers, WHO, Paris, France, 3rd edition, 2007.

[19] WHO, Urinary Iodine Concentrations for Determining Iodine Status Deficiency in Populations, VMNIS, World Health Organization, Geneva, Switzerland, 2013.

[20] K. E. Charlton, L. Gemming, H. Yeatman, and G. Ma, "Suboptimal iodine status of Australian pregnant women reflects poor knowledge and practices related to iodine nutrition," Nutrition, vol. 26, no. 10, pp. 963-968, 2010.

[21] G. Ersino, H. Tadele, A. Bogale, C. Abuye, and B. J. Stoecker, "Clinical assessment of goiter and low urinary iodine concentration depict presence of severe iodine deficiency in pregnant Ethiopian women: a cross-sectional study in rural Sidama," Ethiopian Medical Journal, vol. 51, no. 2, pp. 133-141, 2013.

[22] Y. Mezgebu, A. Mossie, P. N. Rajesh, and G. Beyene, "Prevalence and severity of iodine deficiency disorder among children 612 years of age in shebe senbo district, jimma zone, southwest ethiopia," Ethiopian Journal of Health Sciences, vol. 22, no. 3, pp. 196-204, 2012. 
[23] M. Girma, E. Loha, A. Bogale, N. Teyikie, and C. Abuye, "Iodine deficiency in primary school children and knowledge of iodine deficiency and iodized salt among caretakers in Hawassa Town: Southern Ethiopia," Ethiopian Journal of Health Development, vol. 26, no. 1, pp. 30-35, 2012.

[24] M. Murcia, M. Rebagliato, M. Espad et al., "Iodine intake in a population of pregnant women: INMA mother and child cohort study, Spain," Journal of Epidemiology \& Community Health, vol. 64, no. 12, pp. 1094-1099, 2010.

[25] C. Mian, P. Vitaliano, D. Pozza et al., "Iodine status in pregnancy: role of dietary habits and geographical origin," Clinical Endocrinology, vol. 70, pp. 776-780, 2009.

[26] M. Alvarez-Pedrerol, N. Ribas-Fitó, R. García-Esteban et al., "Iodine sources and iodine levels in pregnant women from an area without known iodine deficiency," Clinical Endocrinology, vol. 72, no. 1, pp. 81-86, 2010.

[27] L. M. Bodnar and A. M. Siega-Riz, "A diet quality index for pregnancy detects variation in diet and differences by sociodemographic factors," Public Health Nutrition, vol. 5, no. 6, pp. 801809, 2002.

[28] G. Stilwell, P. J. Reynolds, V. Parameswaran, L. Blizzard, T. M. Greenaway, and J. R. Burgess., "The influence of gestational stage on urinary iodine excretion in pregnancy," Journal of Clinical Endocrinology and Metabolism, vol. 93, pp. 1737-1742, 2008.

[29] E. Ainy, A. Ordookhani, M. Hedayati, and F. Azizi, "Assessment of intertrimester and seasonal variations of urinary iodine concentration during pregnancy in an iodine-replete area," Clinical Endocrinology, vol. 67, pp. 577-581, 2007.

[30] L. Habimana, K. E. Twite, P. Wallemacq et al., "Iodine and iron status of pregnant women in Lubumbashi, Democratic Republic of Congo," Public Health Nutrition, vol. 16, no. 8, pp. 1362-1370, 2013.

[31] A. L. Brantsæter, M. H. Abel, M. Haugen, and H. M. Meltzer, "Risk of suboptimal iodine intake in pregnant norwegian women," Nutrients, vol. 5, no. 2, pp. 424-440, 2013.

[32] K. J. Schulze, K. P. West Jr., L. A. Gautschi et al., "Seasonality in urinary and household salt iodine content among pregnant and lactating women of the plains of Nepal," European Journal of Clinical Nutrition, vol. 57, pp. 969-976, 2003.

[33] A. O. Kutlu and C. Kara, "Iodine deficiency in pregnant women in the apparently iodine-sufficient capital city of Turkey," Clinical Endocrinology, vol. 77, pp. 615-620, 2012.

[34] J. Fisher, T. Tran, B. Biggs et al., "Iodine status in late pregnancy and psychosocial determinants of iodized salt use in rural northern Viet Nam," Bulletin of the World Health Organization, vol. 89, pp. 813-820, 2011.

[35] B. S. Hetzel, "The development of a global program for the elimination of brain damage due to iodine deficiency," Asia Pacific Journal of Clinical Nutrition, vol. 21, no. 2, pp. 164-170, 2012.

[36] S. Yadav, S. K. Gupta, M. M. Godbole et al., "Persistence of severe iodine-deficiency disorders despite universal salt iodization in an iodine-deficient area in northern India," Public Health Nutrition, vol. 13, no. 3, pp. 424-429, 2009.

[37] M. Andersson, B. De Benoist, F. Delange, J. Zupan, and WHO Secretariat, "Prevention and control of iodine deficiency in pregnant and lactating women and in children less than 2years-old: conclusions and recommendations of the technical consultation," Public Health Nutrition, vol. 10, no. 12, pp. 16061611, 2007. 


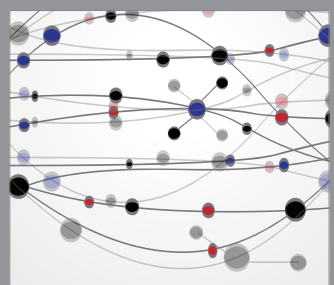

The Scientific World Journal
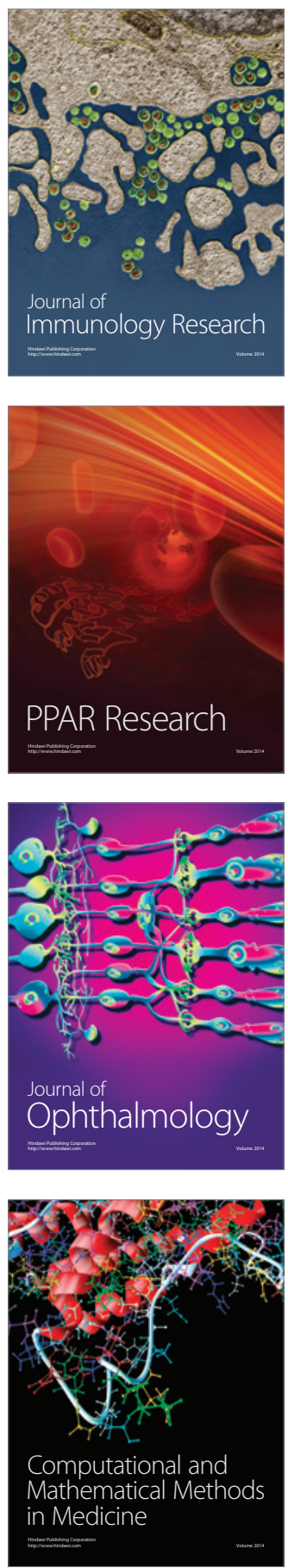

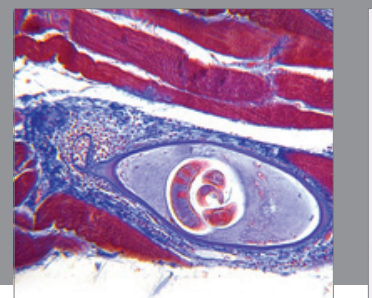

Gastroenterology

Research and Practice
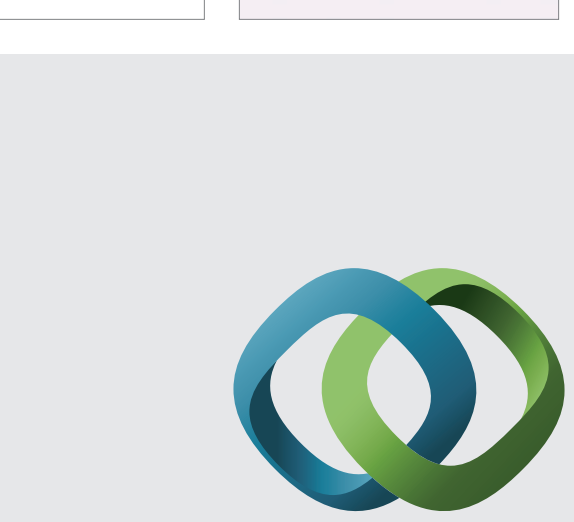

\section{Hindawi}

Submit your manuscripts at

http://www.hindawi.com
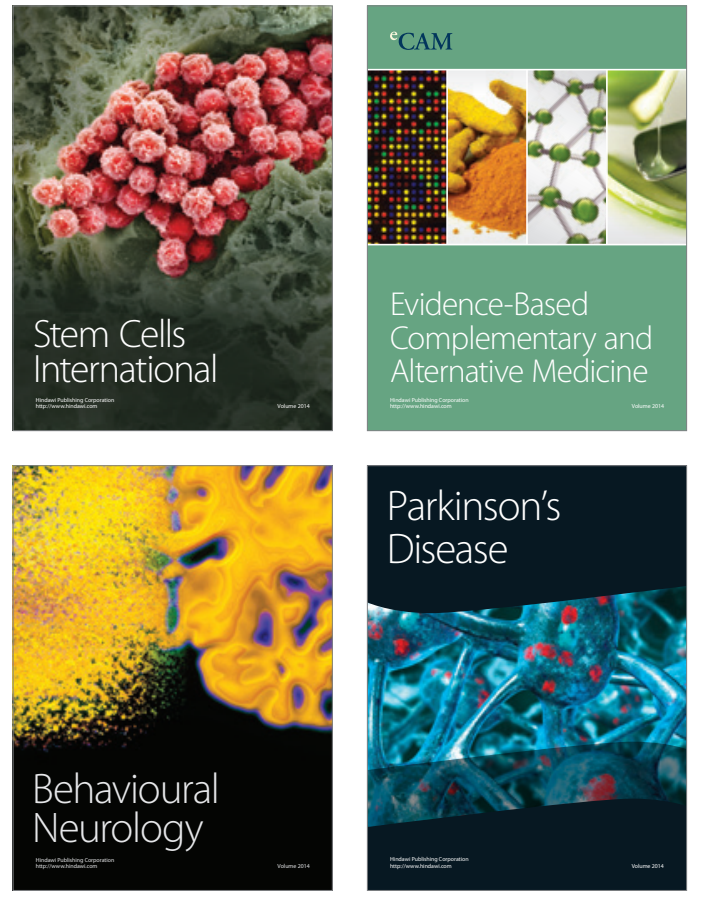
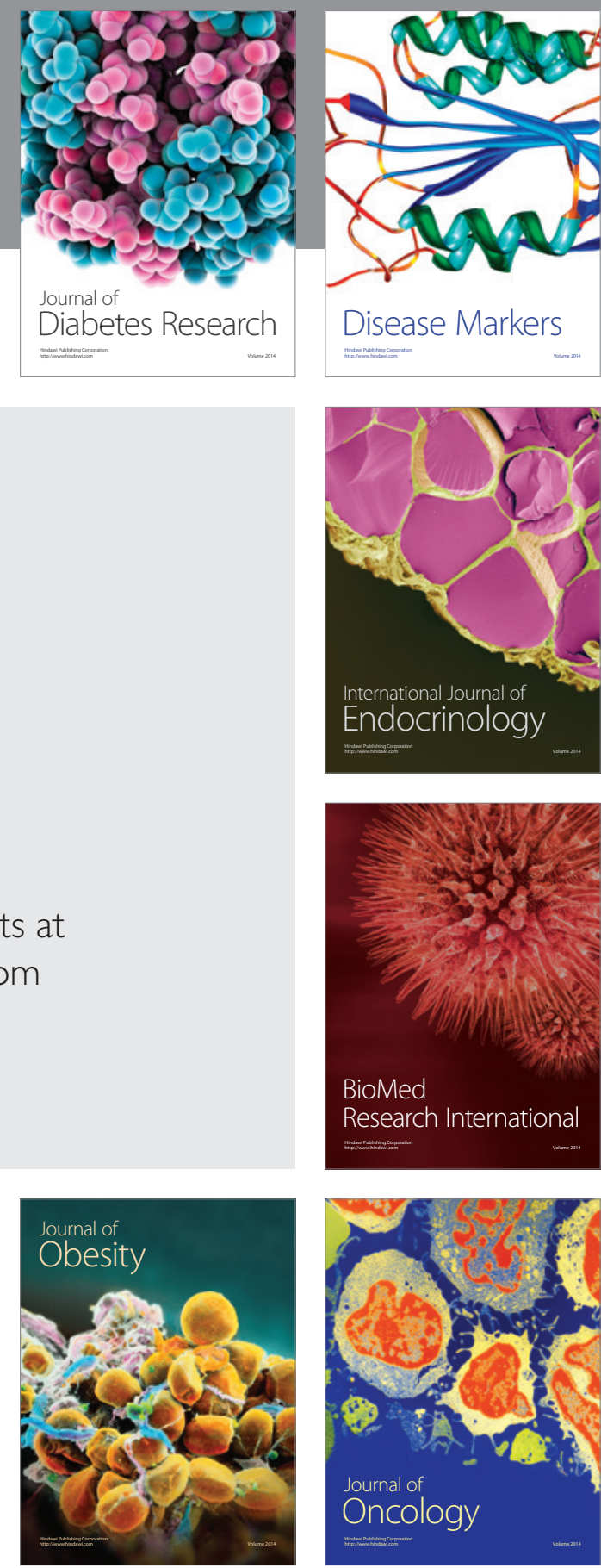

Disease Markers
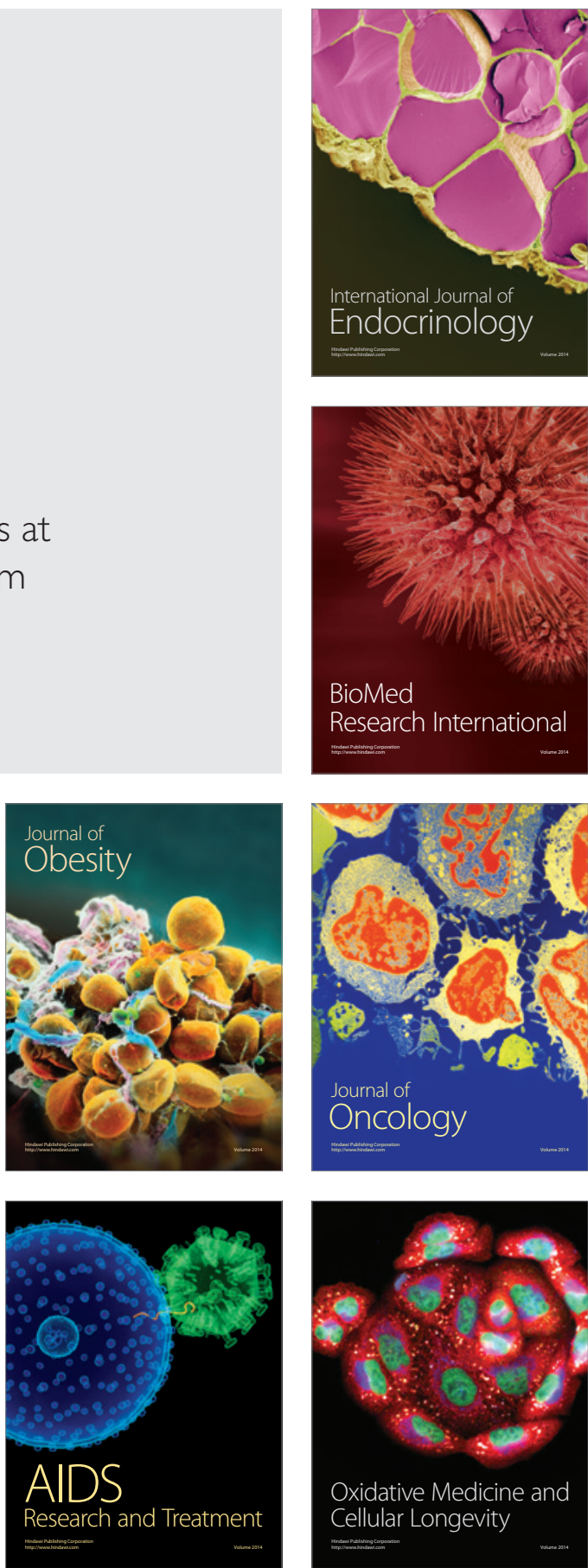